\title{
A Study of Socio-Economic Status (SES) Associated with Epidemiology of Tuberculosis in General Population of District Buner, Khyber Pakhtunkhwa (KPK), Pakistan
}

\author{
Jehangir Khan1*, Fatima Aslam1, Bakht Tarin Khan1, Syyed Ishtiaq Anjum², \\ Faiz-Ur-Rehman'2, Waqas Ahmad Shams' ${ }^{1}$, Zaheer Ahmad ${ }^{1}$ \\ ${ }^{1}$ Zoology Department, Buner Campus, Abdul Wali Khan University Mardan (AWKUM), \\ Mardan, Pakistan \\ 'Zoology Department, Kohat University of Science and Technology, Kohat (KUST), Pakistan \\ Email: Abu amna2013@hotmail.com, irfanaslam909@yahoo.com, rehmansufa@yahoo.com
}

Received 14 April 2015; accepted 29 April 2015; published 5 May 2015

Copyright (C) 2015 by authors and OALib.

This work is licensed under the Creative Commons Attribution International License (CC BY). http://creativecommons.org/licenses/by/4.0/

(c) (i) Open Access

\section{Abstract}

Objectives: Tuberculosis (TB) is endemic in Pakistan ranking fifth amongst the twenty two endemic countries. Historically, TB has been associated with poverty and low socioeconomic status (SES). This study focuses on the association of SES with prevalence of TB in general population of district Buner, Khyber Pakhtunkhwa, Pakistan. Material and Methods: A cross-sectional survey was conducted in Government and Private health care centers during 2010-2013 in district Buner, KPK. TB rates were calculated in relation to SES. Result: The data analysis resulted in 1079 positive cases consisting male $(n=445,41.24 \%)$ and female $n=(634) ; 58.8 \%$. The highest occurrence of TB (306/1079: 28.4\%) was observed in the group 15 - 45 years followed by the group below 15 years (85/1079:7.9\%) in males. The female group in range of $15-45$ years (251/1079: 23.3\%) had maximum TB followed by the group above 45 years (235/1079: $21.8 \%$ ). The male patients with no education were more in number (152/445: $34.16 \%)$ to TB infection as compared to patients with primary (124/445: 27.9\%), secondary (111/445: 34.16\%) and higher education (58/ 445: 13\%). Likewise the highly qualified female patients suffered only $3.5 \%$ from TB where as those having no education had maximum infection (49\%) followed by primary educated (37.85\%) patients. The minimum number of patients (300/1079: $27.8 \%)$ suffering from TB were reported in high income family followed by middle (325/1079: 30\%) and low income (454/1079: 42\%) families. The maximum incidence of TB (320/1079: 28.7\%) was found in 2010 followed by 2011 (289/1079: 26.8\%), 2012 (268/1079: 24.7\%) and 2013 (213/1079: 19.7\%) respectively. Conclu-

\footnotetext{
${ }^{*}$ Corresponding author.
} 
sions: This result shows that there is deep association between the TB infection and the SES among the public. High infection rates of TB in district Buner may reflect ignorance, no early medical care, poor hygiene, poor nutritional status, economic depressions, lack of proper health facility and knowledge regarding the treatment. Screening for TB (to diagnose latent TB infection), education and good SES remain the most important tools to reduce the risk of TB progression among the general populations in a region.

\section{Keywords}

Mycobacterium tuberculosis, Epidemiology, SES, TB Centers, Buner

Subject Areas: Infectious Diseases, Public Health

\section{Introduction}

Tuberculosis (TB) is caused by several species of gram-positive bacteria known as tubercle bacilli or Mycobacterium tuberculosis complex (MTBC). MTBC includes obligate human pathogens such as Mycobacterium tuberculosis and Mycobacterium africanum, as well as organisms adapted to various other species of mammal [1]. TB has been a gigantic health issue in the world for a long time. In spite of the fact that TB incidence declined steadily during the second half of the $20^{\text {th }}$ century in the developed world, the Tuberculosis (TB) remained an important public health problem in the less developed world till now, because the global TB control relied on a 100-year-old diagnostic method (i.e. sputum smear microscopy) of poor sensitivity [2] [3]. Approximately 10 million new cases and a pool of two billion latently infected individuals are reported annually [1]. Among all the reported TB cases from all over the world, eighty-five percent of these TB cases are concentrated in Asia and Africa where there is a lack of education, health care infrastructure, poverty and overcrowding [4]. Pakistan is ranked fifth amongst the twenty two countries designated to be highly burdened by TB and accounts for $63 \%$ of the TB burden in the World Health Organization (WHO) Eastern Mediterranean Region [5]. According to the revised WHO estimates the incidence of TB in Pakistan is 230 per 100,000. The prevalence and mortality are 310 per 100,000 and 39 per 100,000 respectively. This indicates 410,000 incident cases of TB and 69,000 TB deaths in Pakistan every year [6].

Key structural determinants of TB epidemiology include global socioeconomic inequalities, high levels of population mobility, rapid urbanization and population growth. These conditions give rise to unequal distributions of key social determinants of TB, including food insecurity and malnutrition, poor housing and environmental conditions, and financial, geographic, and cultural barriers to health care access. These social determinants are among the key risk factors for TB [7]. For example, poor ventilation and overcrowding in homes, workplaces, and communities increase the likelihood of uninfected individuals being exposed to TB infection [8]-[10]. Poverty, malnutrition, and hunger may increase susceptibility to infection, disease, and severity of clinical outcome [7]. Individuals with TB symptoms such as a persistent cough often face significant social and economic barriers that delay their contact with health systems in which an appropriate diagnosis might be made, including difficulties in transport to health facilities, fear of stigmatization if they seek a TB diagnosis, and lack of social support to seek care when they fall sick [11] [12]. Although DOTS (directly observed treatment, shortcourse) has pioneered the use of a patient's social network to improve treatment adherence, a social determinant's framework also highlights how lack of hope for the future, driven by poverty, might also foster high rates of treatment default that undermine TB control [13].

There are very few studies in Pakistan that have reported the socio-economic aspects of this deadly disease in the country. In the present study, we have looked into the socio-demographic characteristics of patients of tuberculosis and its epidemiology in District Shangla, Khyber Pakhtunkhwa.

\section{Material and Methods}

\subsection{Study Design and Population}

Buner is a district of KPK province in Pakistan, having geographic coordinates of $34^{\circ} 23^{\prime} 39.42$ " North latitude 
and $72^{\circ} 36^{\prime} 54.42^{\prime \prime}$ East longitude. It is a small mountain valley, with rivers (Barandu and Daggar), canal and streams, dotted with villages and divided into seven sub divisions. The Mora Hills and the Ilam range divide Buner from the Swat Valley. A cross sectional survey was conducted during 2010 to 2013 in public and private health care facilities of district Buner, KPK Pakistan.

\subsection{Sampling Technique}

\subsubsection{Selection of Health Care Facility}

Private tertiary care hospitals and government health care facilities (DHQ Buner) were selected. In addition, general practitioners working independently in selected Union Councils (UCs) were also included in the study. Patients belonging to low socioeconomic class more likely visit public hospitals and general practitioners' clinics as compared to patients from middle to higher socioeconomic class who usually prefer private hospitals as a source of treatment.

\subsubsection{Data Collection}

Data was collected through a self structured questionnaire. The questionnaire included two parts; the first part aimed to collect the socio-demographic information and professional characteristics of patients. The second part focused on the disease and intended to assess the clinical knowledge of the TB. The income level of patients was categorized in three groups (low income family: <5000, middle income family: 6000 - 9000, and high income family: >9000 Pakistani Rupees per person per month). No incentive was given to any participant included in this study. The study was approved by the Ethical review Committee of the Department of Zoological Sciences Abdul Wali Khan University Mardan (AWKUM), Buner Campus, KPK Pakistan.

\subsection{Prevalence Rate}

The prevalence rate was determined by using the following formula:

$$
\text { Prevalence rate }=\text { No. of TB patients } / \text { Total no. of patients } \times 100
$$

\section{Results}

There came out to be 1079 TB positive cases. Out of 1079 positive cases, 445 were male (41.2\%) and 634 (58.8\%) female. Among the males, the highest occurrence of TB infections (28.4\%) was observed in the age group of 15 - 45 years followed by the group below 15 years (7.9\%) and lowest in the age group above 45 years. Similarly in the females, the highest prevalence of TB (23.3\%) was found in the age group of 15 - 45 years followed by the group above 45 years (21.8\%) (Figure 1). Regarding economic factor, all the patients were investigated for their socioeconomic status (SES), interestingly; it was found that persons suffering from tuberculosis were more frequently belonged to the low socioeconomic status (SES) as compared to the individuals having good/high SES. Among the three categories, an inverse relation was found in the monthly income and the epidemiology of TB infection, the low income family members suffered more (42\%) followed by middle income family (30\%) and high income family (27.8\%) (Figure 2). One of the important aspects of the present research is the foundation of deep relation between education and prevalence of TB among the population. Among the males, the maximum TB cases (34.16\%) were observed in the individuals with no education followed by primary educated (27.9\%) and secondary educated (24.94\%) patients. Very less (13\%) TB cases were observed in people with the higher secondary education. A similar trend of epidemiology of TB was noticed in the females, the highly qualified individuals suffered only 3.5\% from TB where as the illiterate had maximum infection (49\%) followed by primary educated (37.85\%) individuals (Figure 3). The maximum incidences of TB (320/1079: 28.7\%) was found in 2010 followed by 2011 (289/1079: 26.8\%), 2012 (268/1079: 24.7\%) and 2013 (213/1079: 19.7\%) (Figure 4). The pathogenesis and the multi-factorial aspects of the TB infection have been explained explicitly (Figure 5).

\section{Discussion}

The present modeling exercise is the first attempt in District Buner, PKP, to study the epidemiology and socio-economic aspects of TB infected individuals. Our study showed that the persons suffering from tuberculosis 


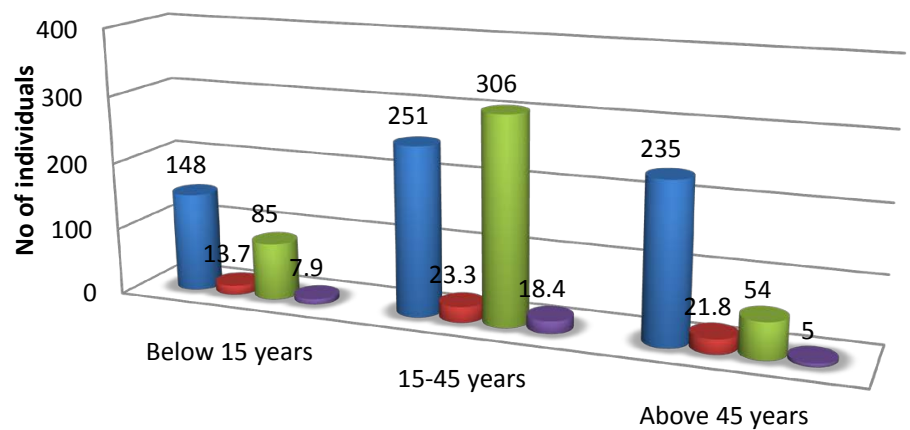

\begin{tabular}{|l|c|c|c|}
\cline { 2 - 4 } \multicolumn{1}{c|}{} & Below 15 years & $15-45$ years & Above 45 years \\
\hline$\square$ Female & 148 & 251 & 235 \\
\hline Percentage in Female & 13.7 & 23.3 & 21.8 \\
\hline Male & 85 & 306 & 54 \\
\hline$\square$ Percentage in Male & 7.9 & 18.4 & 5 \\
\hline
\end{tabular}

Figure 1. Age wise prevalence of TB infection in district Bunir $(\mathrm{n}=1079)$.

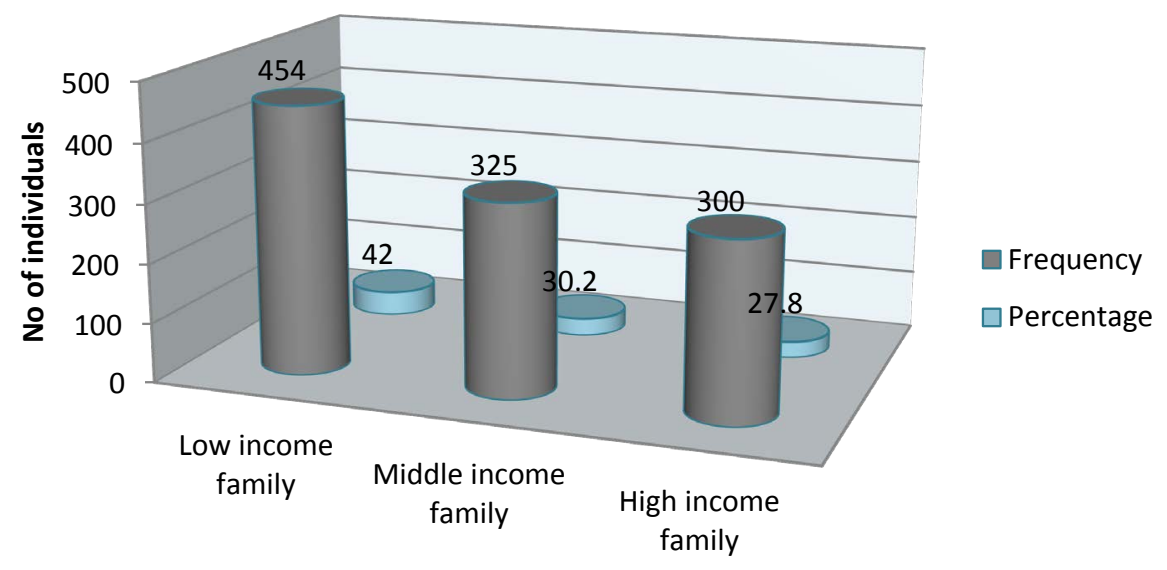

Figure 2. Epidemiology of TB in families having different income level ( $\mathrm{n}=1079)$.

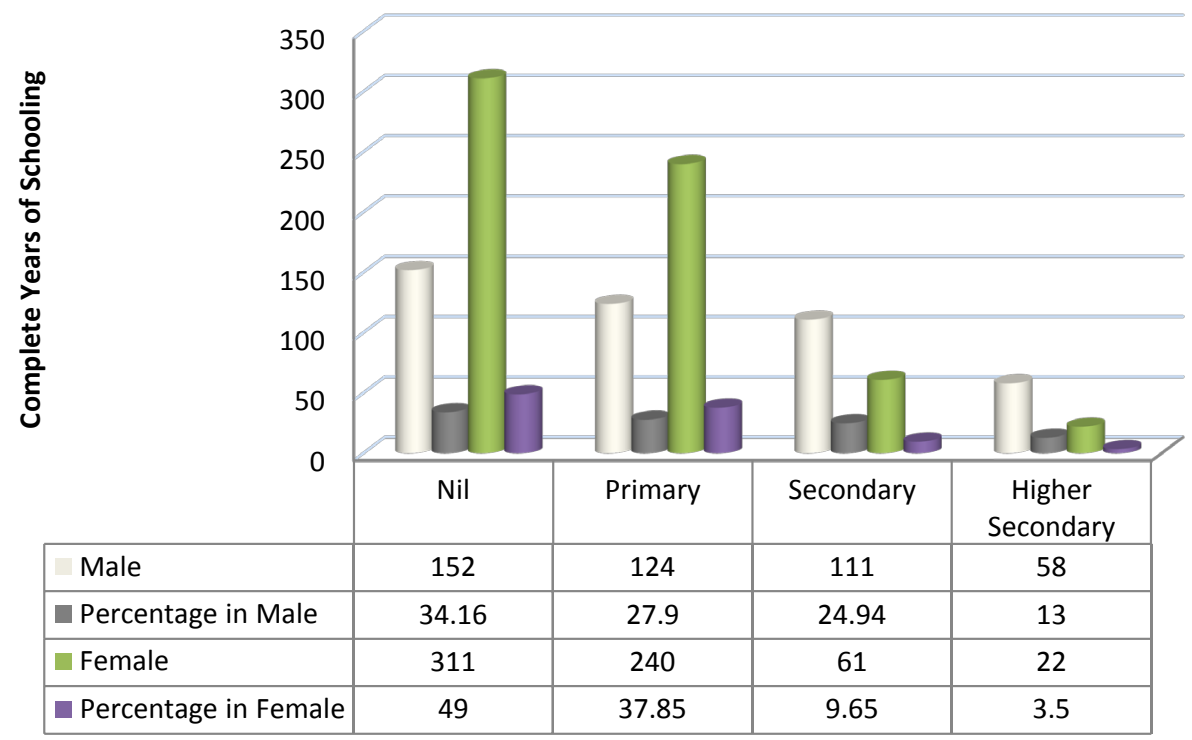

Figure 3. Occurrence of TB in the patients having different categories of education $(n=1079)$. 


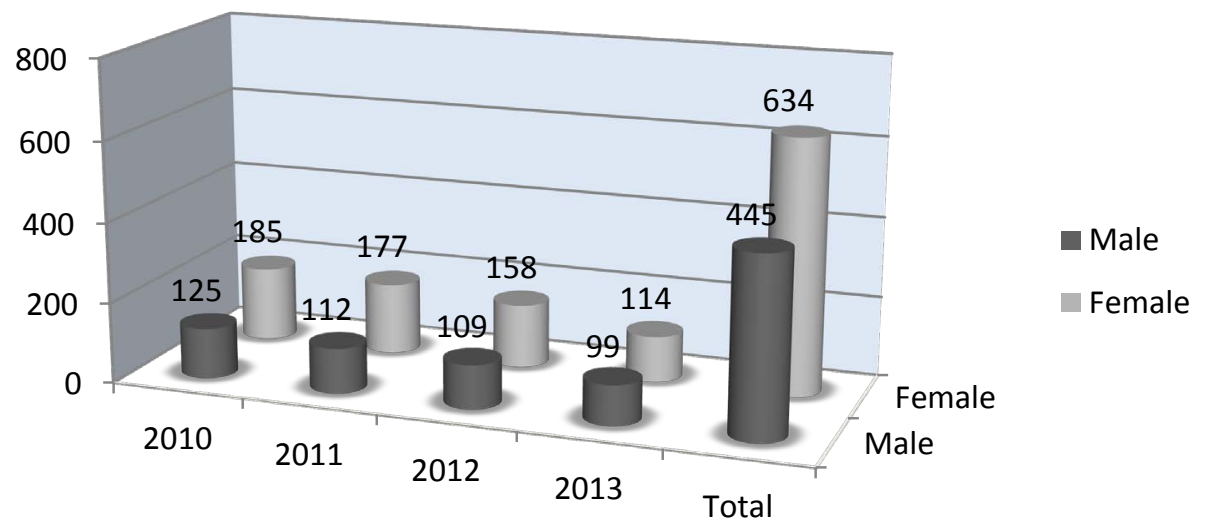

Figure 4. Year wise (2010 to 2013) prevalence of TB infections.
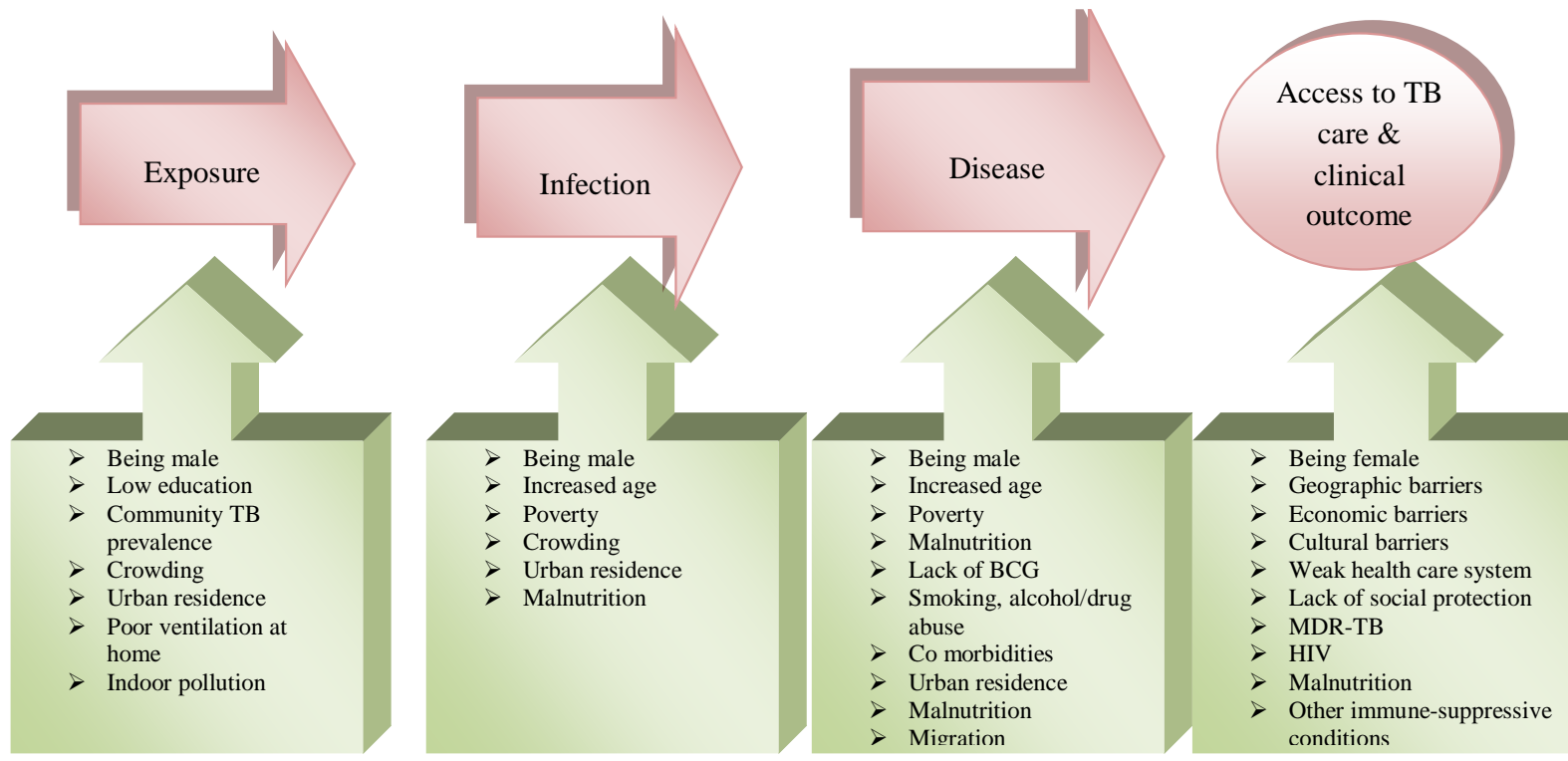

Figure 5. Risk factors associated with different stages of TB pathogenesis and the subsequent cause of epidemiology.

were more frequently found in the low socio-economic status. The age, level of education, poverty, and number of individuals per house was found to be independently and significantly associated with a higher risk of TB. The highest epidemiology of TB in low SES societies may be the poor knowledge of TB, risks of infection and dissemination, and with inadequate and/or delayed availability of health care.

Furthermore, this study found a strong association between incidence of TB and poverty, those who belonged to low income family suffered more (42\%) from TB infection as compared to middle (30\%) and high income family (21.8\%) (Figure 2). It was observed that the patients belonging to poor family were also being deprived of education and likewise the epidemiology of TB was more (males: $12.2 \%$, females: $28.8 \%$ ) in the families having no education (Figure 3), our results are consistent with previous studies [5] [14]-[16]. However, a report [17] has shown that poverty-based malnutrition increases the risk of TB even six to ten-fold [18]. Moreover, a study [19] on socioeconomic impact of TB and the illiteracy has revealed that tuberculosis imposes high direct and indirect costs on the patients leading to loss of wages for an average of 3 months and subsequently leads to school drop-outs in about 20\% children [16]. Our study further suggests about the enhancing anti-TB efforts, also, in addition with successful implementation of tuberculosis control programs to control further the spreading of TB.

We also found (minor observation) that maximum number of patients belonged to highly urbanized and crowded areas in the district. In this regard a number of studies [20] [21] have reported that the rapid urbanization in developing countries and low socioeconomic status (SES) of individuals are the significant contributors 
in the recent increase of TB epidemiology [22] [23]. In a study among urban residents of New York City, TB infection positivity was present in $5.5 \%$ in the area of highest socio-economic status versus $22.4 \%$ in the lowest [16]. Our study also found that the people with lower SES had a higher likelihood of being exposed to crowded and less ventilated places. A similar report [24] has found that the marginalized populations were at higher chance of getting infected with TB mostly because of crowded living conditions. The current study observed a multifactorial based approach to the risk of TB infection which has been explained (Figure 5).

The current study found highest occurrence of TB infection (306/1079: 28.4\%) in the group having 15 - 45 years followed by the individuals under 15 years (85/1079: 7.9\%) in males, while the females 15 - 45 years had highest TB infection (251/1079: 23.3\%) followed by the group above 45 years (235/1079: 21.8\%) (Figure 1). Ayaz et al. 2012 [25] recorded the highest occurrence of TB (68.96\%) in age group 10 - 20 years, followed by 21 - 40 years (35.29\%) and the lowest was recorded (15.06\%) in individuals with age more than 40 years. Our results are incompatible with Ayaz et al. 2012 but congruent with Ahmad et al. 2013 [26], who reported the maximum numbers of patients in age of 15 - 64 (82.72\%), Akhtar et al. 2014 [27] also documented the similar observations as they reported the highest rate of TB infection (46\% and 46.82\%) in age of 31 - 45 years followed by 46 - 60 years (32.11\% and $34.10 \%$ ) in male and female respectively. This study reported low infection of TB in male (445: 41.24\%) as compared to female (634: 58.8\%) (Figure 1), our results are in agreement with a more recent report of Ahmad et al. 2014 [28], who observed the highest occurrence of TB in female (59\%) as compared to male (41\%), the high occurrence (84\%) of TB was recorded in age group 15 - 54 years, and the lowest was recorded (8\%) in age group $0-14,55$ and above years. Our findings are also congruent with the previous reports [29]-[31]. Among the four years study, the highest epidemiology (310/1079: 28.7\%) of TB infection was found in 2010 followed by 2011 (289/1079: 26.8\%), 2012 (268/1079: 24.8\%) and 2013 (213/1079: 19.7\%) as shown in Figure 4. Our study observed low rate of TB incidence in a four year survey period and is one of the lower reports previously documented from the country [26]-[31].

The reduction in burden of TB in the subsequent years (2010-2013) may be suggested as due to the developing trend of education and sense about the care of TB (because once it was ignored). Moreover, Buner, being an industrial area, providing jobs and employment to the local people and hence the overall financial status might has been substantially improved. Also, the government interest in establishing the TB centers (easily accessible) for free treatment and availability of medicines, and the campaign of cleanliness everywhere has significantly reduced the level of TB epidemiology.

\section{Conclusion}

Although much is known about the epidemiology of tuberculosis, relatively little is known of its economic and social impacts specifically in Buner. The illness and death caused by the disease have far reaching economic, psychological, and social consequences. The present study indicates the existence of interactions between SES and TB infections. Most public health efforts are focused on control of tuberculosis through treatment of patients. The current predominantly treatment-based approach to tuberculosis control cannot be expected to eradicatetuberculosis unless matching and forceful efforts in prevention through improvement in socio-economic status are also initiated. The establishment of further easily accessible health care centers for frees diagnosis and treatment of TB, the campaign about the awareness of TB among the general population and cleanliness will reduce the TB infection rate sufficiently. Additionally, to achieve the goal of TB elimination, TB programs and future research must also include a focus on prevention through diagnosis and treatment of latent tuberculosis infection (LTBI).

\section{Competing Interest}

The authors of this research declare that they have no competing interest.

\section{Acknowledgements}

The authors highly acknowledge the collaboration of Medical Superintendent of DHQ Buner, the heads of health care centers, Buner, KPK, Pakistan.

\section{Authors' Contribution}

Conceived and designed the research: JK. Performed the experiments: FA. Analyzed the data: JK FR FA. Con- 
tributed reagents/materials/analysis tools: JK. Wrote the paper: JK FA. Provided suggestions and comments on the manuscript: JK FR.

\section{References}

[1] Comas, I. and Gagneux, S. (2009) The Past and Future of Tuberculosis Research. PLOS Pathogens, 5, 1-7. http://dx.doi.org/10.1371/journal.ppat.1000600

[2] Kaufmann, S.H. and Parida, S.K. (2007) Changing Funding Patterns in Tuberculosis. Nature Medicine, 13, $299-303$. http://dx.doi.org/10.1038/nm0307-299

[3] WHO (2010) WHO Report 2010. Global TB Control. WHO/HTM/TB/2010.7. Geneva.

[4] World Health Organization (2011) WHO Report 2011. Global TB Control. WHO/HTM/TB/2011.16. Geneva.

[5] Naseer, M., Khawaja, A., Pethani, A.S. and Aleem, S. (2013) How Well Can Physicians Manage Tuberculosis? A Public-Private Sector Comparison from Karachi, Pakistan. BMC Health Services Research, 13, 439. http://dx.doi.org/10.1186/1472-6963-13-439

[6] World Health Organization (2009) Global Tuberculosis Control-Epidemiology, Strategy, Financing. WHO Report 2009, Geneva. (WHO/HTM/TB/2009.411).

[7] Hargreaves, J.R., Boccia, D., Evans, C.A., Adato, M., Petticrew, M. and Porter, J.D.H. (2011) The Social Determinants of Tuberculosis: From Evidence to Action. American Journal of Public Health, 101, 654-662. http://dx.doi.org/10.2105/AJPH.2010.199505

[8] Hill, P.C., Jackson-Sillah, D., Donkor, S.A., Out, J., Adegbola, R.A. and Lienhardt, C. (2006) Risk Factors for Pulmonary Tuberculosis: A Clinic-Based Case Control Study in the Gambia. BMC Public Health, 6, 156. http://dx.doi.org/10.2105/AJPH.2010.199505

[9] Boccia, D., Hargreaves, J., Ayles, H., Fielding, K., Simwinga, M. and Godfrey-Faussett, P. (2009) Tuberculosis Infection in Zambia: The Association with Relative Wealth. American Journal of Tropical Medicine and Hygiene, 80, $1004-$ 1011.

[10] Baker, M., Das, D., Venugopal, K. and Howden-Chapman, P. (2008) Tuberculosis Associated with Household Crowding in a Developed Country. Journal of Epidemiology and Community Health, 62, 715-721. http://dx.doi.org/10.1136/jech.2007.063610

[11] Kanara, N., Cain, K.P., Chhum, V., Eng, B., Kim, S., Keo, S., et al. (2009) Association between Distance to HIV Testing Site and Uptake of HIV Testing for Tuberculosis Patients in Cambodia. International Journal of Tuberculosis and Lung Disease, 13, 226-231.

[12] Somma, D., Thomas, B.E., Karim, F., Kemp, J., Arias, N., Auer, C., et al. (2008) Gender and Socio-Cultural Determinants of TB-Related Stigma in Bangladesh, India, Malawi and Colombia. International Journal of Tuberculosis and Lung Disease, 12, 856-866.

[13] Kim, J., Pronyk, P., Barnett, T. and Watts, C. (2008) Exploring the Role of Economic Empowerment in HIV Prevention. AIDS, 22, S57-S71. http://dx.doi.org/10.1097/01.aids.0000341777.78876.40

[14] Wanyeki, I., Olson, S., Brassard, P., Menzies, D., Ross, N., Behr, M. and Schwartzman, K. (2006) Dwellings, Crowding, and Tuberculosis in Montreal. Social Sciences and Medicines, 63, 501-511. http://dx.doi.org/10.1016/j.socscimed.2005.12.015

[15] Olson, N.A., Davidow, A.L., Winston, C.A., Chen, M.P., Gazmararian, J.A. and Katz, D.J. (2012) A National Study of Socioeconomic Status and Tuberculosis Rates by Country of Birth, United States, 1996-2005. BMC Public Health, 12, 365. http://dx.doi.org/10.1186/1471-2458-12-365

[16] Gupta, D., Das, K., Balamughesh, T., Aggarwal, A.N. and Jindal, S.K. (2004) Role of Socio-Economic Factors in Tuberculosis Prevalence. Indian Journal of Tuberculosis, 51, 27-31.

[17] Narasimhan, P., Wood, J., MacIntyre, C.R. and Mathai, D. (2013) Risk Factors for Tuberculosis. Pulmonary Medicine, 2013, 1-11. http://dx.doi.org/10.1155/2013/828939

[18] Lonnroth, K., Williams, B.G., Cegielski, P. and Dye, C. (2010) A Consistent Log-Linear Relationship between Tuberculosis Incidence and Body Mass Index. International Journal of Epidemiology, 39, 149-155. http://dx.doi.org/10.1093/ije/dyp308

[19] Rajeshwari, R., Balasubramanian, R., Muniyandi, M., Geetharamani, S., Theresa, X. and Venkatesan, P. (1999) Socioeconomic Impact of Tuberculosis on Patients and Family in India. International Journal of Tuberculosis and Lung Disease, 3, 869-877.

[20] Eisenberg, J.N.S., Desai, M.A., Levy, K., Bates, S.J., Liang, S., Naumoff, K. and Scott, J.C. (2007) Environmental Determinants of Infectious Disease: A Framework for Tracking Causal Links and Guiding Public Health Research. Envi- 
ronmental Health Perspectives, 115, 1216-1223. http://dx.doi.org/10.1289/ehp.9806

[21] Dye, C. and Williams, B.G. (2010) The Population Dynamics and Control of Tuberculosis. Science, 328, 856-861. http://dx.doi.org/10.1126/science.1185449

[22] Onnroth, K.L., Jaramillo, E., Williams, B.G., Dye, C. and Raviglione, M. (2009) Drivers of Tuberculosis Epidemics: The Role of Risk Factors and Social Determinants. Social Science and Medicine, 68, 2240-2246. http://dx.doi.org/10.1016/j.socscimed.2009.03.041

[23] Muniyandi, M., Ramachandran, R., Gopi P.G., Chandrasekaran, V., Subramani, R., Sadacharam, K., et al. (2007) The Prevalence of Tuberculosis in Different Economic Strata: A Community Survey from South India. International Journal of Tuberculosis and Lung Disease, 11, 1042-1045.

[24] Grady, O.J., Maeurer, M., Atun, R., Abubakar, I., Mwaba, P., Bates, M., et al. (2011) Tuberculosis in Prisons: Anatomy of Global Neglect. European Respiratory Journal, 38, 752-754. http://dx.doi.org/10.1183/09031936.00041211

[25] Ayaz, S., Nosheen, T., Khan, S., Khan, S.N., Rubab, L. and Akhtar, M. (2012) Pulmonary Tuberculosis: Still Prevalent in Human in Peshawar, Khyber Pakhtunkhwa, Pakistan. Pakistan Journal of Life Sciences, 10, 39-41.

[26] Ahmad, T., Ahmad, S., Haroon, M.Z., Khan, A., Salman, S., Khan, N. and Gul, F. (2013) Epidemiological Study of Tuberculosis. European Academic Research, 1, 1854-1860.

[27] Akhtar, N., Khan, B.T., Khan, J., Saeed, K., Khan, S. and Ahmad, Z. (2014). Prevalence of Tuberculosis: Current Status in Manglawar District Swat, Khyber Pakhtunkhwa, Pakistan. European Academic Research, 1, 5160-5166.

[28] Ahmad, T., Ahmad, K., Naseerullah, Jamal, S.G., Raziullah, Khan, F.M., Khan, S. and Muhammad, R. (2014) A Short Report On Tuberculosis in District Dir (Lower) Khyber Pakhtunkhwa Pakistan. Reviews of Progress, 1, 100-105.

[29] Tauseef, A. and Naiz, A. (2013) Tuberculosis Is Still Prevalent in Women of Gul Abad. International Journal of Scientific Engineering and Research, 1, 95-100.

[30] Shafqat, M. and Jamail, S. (2012) The Distribution of Tuberculosis Patients and Associated Socio Economic Risk Factors for Transmission of Tuberculosis Disease in Faisalabad City. Asian Journal of Natural and Applied Science, 1, 90 95.

[31] Tauseef, A., Uallah, N. and Kabir, A. (2013) A Descriptive Study of Tuberculosis in Chakdara Town Pakistan. Asian Journal of Natural and Applied Sciences, 2, 98-103. 